\title{
Prevalence of Intestinal Parasites in a Low-Income Texas Community
}

\author{
Rachael Singer, ${ }^{1 \star}$ Teena Huan $\mathrm{Xu},{ }^{2}$ Lauren Nicholas S. Herrera, ${ }^{2}$ Maria Jose Villar, ${ }^{2}$ Kasey M. Faust, ${ }^{3}$ Peter J. Hotez, ${ }^{2}$ \\ Abigail R. A. Aiken, ${ }^{1}$ and Rojelio Mejia ${ }^{2}$ \\ ${ }^{1}$ Lyndon B. Johnson School of Public Affairs, The University of Texas at Austin, Austin, Texas; ${ }^{2}$ Department of Pediatrics: Tropical Medicine, \\ National School of Tropical Medicine, Baylor College of Medicine, Houston, Texas; ${ }^{3}$ Department of Civil, Architectural and Environmental \\ Engineering, The University of Texas at Austin, Austin, Texas
}

\begin{abstract}
Strongyloidiasis affects an estimated hundreds of millions of people worldwide, with infection possibly persisting for life without appropriate therapy because of the helminth's unique autoinfection cycle. Like other soiltransmitted helminths, because of the environmental conditions required for the life cycle of Strongyloides stercoralis, this parasite is endemic to tropical, subtropical, and temperate countries and areas with inadequate sanitation infrastructure. Given continued poverty and that nearly one in five American homes are lacking proper sanitation systems, many U.S. regions are at risk for intestinal parasites. A central Texas community was chosen as the study site, given previous reports of widespread sanitation failure, degree of poverty, and community willingness to participate. A total of 92 households were surveyed and residents tested for nine intestinal parasites using a multi-parallel quantitative real-time polymerase chain reaction and ELISA serology. From 43 stool samples, 27 (62.8\%) tested positive for Blastocystis spp. and one (2.3\%) for Giardia lamblia. From 97 serum samples, Strongyloides serology detected $16(16.5 \%)$ positive individuals. These high rates of heterokont and helminthic laboratory findings in a peri-urban central Texas community suggest several key policy implications, including that strongyloidiasis should be added to the Texas notifiable conditions list, that clinical suspicion for this infection should be heightened in the region, and that residents without access to functioning and sustainable sanitation infrastructure should be provided that access as a basic human right and to promote public health.
\end{abstract}

\section{INTRODUCTION}

Intestinal parasitism is an important public health concern worldwide. Gastrointestinal (Gl) parasites are known to disproportionately affect preschool and school-aged children, whereas economically disadvantaged children are at greater risk for recurrent infections. These infections can cause significant disease in children, leading to impaired physical and cognitive development, as well as poor school attendance and academic achievement. ${ }^{1-10}$ Consequently, untreated or recurrent infections can impact future economic potential, perpetuating the cycle of poverty. ${ }^{10}$

Despite these potential adverse outcomes, the prevalence of intestinal parasitism is not well defined in the United States. This lack of information is largely because the prevalence of $\mathrm{Gl}$ parasites within at-risk populations is systematically underestimated because of the lack of national surveillance activities, low sensitivity of standard microscopic stool analysis methods, and lack of clinical suspicion for these infections generally. ${ }^{11-14}$ The present study uses molecular methods as a more sensitive and objective diagnostic technique and operates on the assumption that GI parasites may be present in a variety of population subgroups, especially where conditions of poverty persist.

In addition to being underestimated in many resourcelimited countries, GI parasites are often underreported in the United States. ${ }^{13,15,16}$ At the clinical level, physicians and laboratory technicians do not often suspect, and therefore do not test for intestinal parasitic infections, presumably because of a lack of awareness and deficits in traditional U.S. medical education. At the policy level, most of the intestinal parasitic infections are not reportable by mandate at the state level nor are they voluntarily nationally notifiable at the federal level.

*Address correspondence to Rachael Singer, Lyndon B. Johnson School of Public Affairs, The University of Texas at Austin, 2300 Red River St., P.O. Box Y, Austin, TX 78713. E-mail: rsinger@utexas.edu
Senate bill S. 2675, known as the Study, Treat, Observe, and Prevent (STOP) Neglected Diseases of Poverty Act, was introduced in 2019 to address some of these issues. ${ }^{17}$

As a consequence of widespread neglect and dearth of surveillance activities, the current prevalence of locally acquired Gl parasite infection in the United States is largely unknown. With few contemporary exceptions, the last domestic surveys for these infections were completed in the 1980s and decades prior, when roundworm, hookworm, and whipworm infections, and strongyloidiasis were found throughout the southern United States and Appalachia. ${ }^{18}$ Strongyloides stercoralis, for example, was recognized as endemic to the southeastern United States after studies from the last century detected prevalence rates of approximately $0.1-3.8 \% .{ }^{18}$ In 1914, The Rockefeller Sanitary Commission determined that more than half of the Alabama population was infected with hookworm; by the 1930 s, $32.3 \%$ of specimens sampled from Alabama counties tested positive for hookworm. ${ }^{19,20}$ A followup study in the 1950s determined that hookworm rates generally decreased but persisted in rural Alabama schoolchildren, averaging $17.1 \%$ in the same counties surveyed in $1937 .^{21}$ Current reports indicate that autochthonous S. stercoralis remains endemic in pockets of Appalachia, Los Angeles County, California, and rural Alabama. ${ }^{22-24}$

Extreme poverty and deficiencies in water, sanitation, and hygiene (WASH) have emerged as primary risk factors for parasite infection in the historical literature, ${ }^{18,25}$ such that helminthic and intestinal parasitic infections should be considered as health and economic disparities. A large rise in extreme poverty, defined as cash income of no more than \$2 per person per day, for a month or calendar quarter, has been documented among U.S. households since 1996. ${ }^{26,27}$ According to the most recent American Community Survey, an estimated 470,774 occupied households lack full indoor plumbing, which may include a toilet. ${ }^{28}$ Based on Census Bureau estimates of average household size of 2.6, more than 1.2 million Americans live without the plumbing required for 
basic sanitation. ${ }^{28}$ According to the most recent American Housing Survey, $18.1 \%$ of U.S. homes are not serviced by a public sewer. ${ }^{29}$ Although other sanitation technologies provide adequate service when installed and maintained properly, such alternative wastewater management strategies-for example, septic system or cesspool-have higher incidences of failure in low-income areas as the impracticable burden of installation and maintenance largely falls on the household. ${ }^{30} \mathrm{~A}$ previous study found that human hookworm infection remains endemic in a low-income rural area of Alabama meeting these criteria of absent plumbing and sanitation, or the presence of open sewage. ${ }^{24}$ Through a household survey combined with stool and blood samples, this study aims to characterize the threat of Gl parasites to an unincorporated, peri-urban Texas community with a history of sanitation infrastructure challenges-a common history and present reality shared by many other communities nationwide.

\section{MATERIALS AND METHODS}

Sample population. The study was carried out in Community $A$, an unincorporated, peri-urban community in Guadalupe County, central Texas, containing approximately 400 lots. Unincorporated communities in the United States are areas within a county not serviced by any municipality. Although the nature of unincorporated communities varies greatly across the United States, Texas unincorporated areas are generally of low income and lack some combination of functioning wastewater system, potable drinking water, electricity, and paved roads with drainage. ${ }^{31-33}$ Community $A$ and its neighboring community had previously approached the University of Texas at Austin for assistance collecting data to apply for sanitation grants. Surveys (Ward, Olmedo, Rojas, and Sullivan, unpublished data) from 2010 suggested that $98 \%$ of households in these two communities rely on (mostly professionally installed) septic tanks for wastewater removal. Notably, despite professional installation, $44 \%$ of surveyed households reported signs of septic system failure (clogs, sewage backups, capacity issues, and leaks), potentially due to improper soil type and poor maintenance.

Between March and July 2018, a total of 92 households containing 404 individuals enrolled in the present study, after an exhaustive door-to-door community-wide sampling approach. All accessible and occupied households were eligible to participate. Households were deemed inaccessible if they were gated for privacy, if a no trespassing sign was posted, or if apparently aggressive dogs were present-79 households were inaccessible for one or more of these reasons. Each of 244 accessible households was approached three times by a pair of researchers with English-Spanish language parity, and one household member was invited to participate in the household survey on behalf of all household members. Of all accessible households, 92 (37.7\%) participated in the survey, $82(33.6 \%)$ declined to participate, and 70 (28.7\%) were unresponsive or gave no definitive response after three contact attempts by the research team. All participating households gave informed consent.

The survey was codeveloped by public health and policy scholars and civil engineers to capture built environment data pertinent to health. After a native Spanish speaker translated it to Spanish, the household survey instrument underwent content validation and was pre-deployed by several additional members of our research team to ensure accessibility of the questions and correctness of data collected. The survey instrument included questions regarding sociodemographic and health history for all household members; household socioeconomic status; diarrheal, respiratory, and dermatological disease history; household building and construction characteristics; wastewater and drinking water systems and problems; and other infection risk factors. The survey also asked about the travel history of each resident outside the United States within the past 5 years, and for children whether their birthplace was within the United States. Survey data were collected and managed using REDCap electronic data capture tool. ${ }^{34}$

Individual household residents were eligible to participate in stool and/or blood sample collection if they lived in one of the 92 surveyed households, were at least aged 2 years, and did not report taking an antiparasitic medication in the past year. In total, 43 stool and 97 blood samples were obtained. Informed parental consent was obtained for children younger than 18 years, and informed assent was additionally obtained for children aged at least 7 years. This study was approved by the University of Texas at Austin Institutional Review Board (study number 2017-01-0025) with a Research Collaboration Agreement with Baylor College of Medicine.

Sample collection. Stool samples were self-collected by the individual participants after instructions and materials were provided bilingually, both verbally and in writing. Participants were instructed to fill stool collection containers with approximately $5 \mathrm{~g}$ of stool and store in the provided opaque double-sealed biohazard bags in the refrigerator overnight or until the next scheduled visit (up to several days). All samples were stored in ice coolers immediately after collection and transported to a BSL-2 laboratory at the University of Texas at Austin for storage in $-20^{\circ} \mathrm{C}$ freezers before final transport in dry ice coolers to the Laboratory of Clinical Parasitology and Diagnostics, Baylor College of Medicine, where they were again stored in $-20^{\circ} \mathrm{C}$ freezers.

Whole blood samples were collected by venipuncture by a registered nurse under sterile conditions and were stored in ice coolers immediately after collection and transported to a BSL-2 laboratory at the University of Texas at Austin for storage in $4^{\circ} \mathrm{C}$ refrigerator before final transport in ice coolers to the Laboratory of Clinical Parasitology and Diagnostics, Baylor College of Medicine, where they were again stored in a $4^{\circ} \mathrm{C}$ refrigerator.

Multi-parallel real-time quantitative PCR. DNA was extracted from the frozen stool samples using MP FastPrep spin kits for soil (MP Biomedicals, Santa Ana, CA) after a modified method was developed by the primary investigator, as previously described for Ancylostoma duodenale, Ascaris lumbricoides, Cryptosporidium species, Entamoeba histolytica, Giardia lamblia, Necator americanus, S. stercoralis, and Trichuris trichiura DNA. ${ }^{15}$ Samples were analyzed on an ABI ViiA 7 Real-Time PCR System (Applied Biosystems, Foster City, CA), as previously described. ${ }^{35}$ DNA concentrations were calculated using parasite plasmid standard curves. All controls (positive, negative, and internal control) were performed on subject samples in duplicate. ${ }^{36}$ For Blastocystis, primers were previously designed for a segment of the SSU rRNA gene with the ability to amplify DNA from subtypes 1 to $10 .^{37}$ Standards were prepared for Blastocystis according to the identical protocol previously described for other species. 
Plasmids containing the target sequences were synthesized (Genscript, Piscataway, NJ) and transformed into TOP10 competent Escherichia coli cells (Life Technologies, Grand Island, NY) with subsequent purification, quantitation by spectrophotometry, and serial dilution to make a standard curve (GenBank accession number: J02459). All qPCRpositive samples were reported as parasite DNA concentrations, measuring in femtograms per microliter $(\mathrm{fg} / \mu \mathrm{L})$.

Strongyloides NIE-ELISA IgG. For the detection of S. stercoralis, a previously described NIE-ELISA protocol ${ }^{38}$ was implemented using serum from the 97 participants who provided blood samples. The NIE-ELISA is a recombinant antigen that has shown no cross-reactivity to other helminths. ${ }^{36}$ Any positive laboratory result (quantitative polymerase chain reaction, ELISA) was communicated back to the participant and their primary care provider by a result letter. This letter explained in detail the findings and recommended steps of therapy. Participants were also notified of negative results.

Data analysis. Descriptive statistics were computed to describe community demographic and built environment variables. Molecular and serological data were analyzed using the 2-sided Fisher exact test to identify associations between risk indicators for infection with detected parasite species. In an effort to assess participation bias, we additionally tested for differences in household income between participants who did or did not provide stool or blood samples. Findings were considered statistically significant at an alpha level of 0.05 . All analyses were performed in Stata version 14 (StataCorp. 2015. Stata Statistical Software: Release 14. College Station, TX: StataCorp LP).

\section{RESULTS}

Survey. Table 1 displays descriptive statistics for the study population. Among all residents in the surveyed households, $49.8 \%$ are male and $50.3 \%$ are female, with an age distribution as reported in Table 1. Because age data were not provided for six adults, the total population reflected in Table 1 is 398 of the 404 individuals in the surveyed households.

Diarrhea in the past year was reported by $32.9 \%$ of individuals in the surveyed households, whereas $6.1 \%$ reported a dermatological ailment and $14.8 \%$ reported a respiratory ailment in the past year. Of all residents in the surveyed households, $32.0 \%$ reported that their septic tank overflows or backs up, and $34.2 \%$ reported that their toilet backs up. Several residents additionally noted that septic tanks overflow with rain or flooding and that laundry washing machine water is affected, presumably owing to septic backup. Of 148 children aged $\leq 18$ years, 93.9\% were born in the United States. Of all residents surveyed, $17.2 \%$ reported a travel history outside of the United States within the past 5 years (Figure 1).

As a way of assessing participation bias, we tested for differences in household income between participants who did or did not provide stool or blood samples. After excluding 13 cases with missing household income data, the total population reflected in Table 2 is 391. Among individuals living in a household with monthly income less than $\$ 2,000,21.5 \%$ provided stool and $78.5 \%$ did not, whereas among those individuals living in a household with monthly income greater than $\$ 2,000,5.5 \%$ provided a stool sample and $94.5 \%$ did not $(P<0.001$, Table 2). Overall, $67.4 \%$ of individuals who provided stool samples live in households reporting a monthly income less than $\$ 2,000$, in the context of a community where $34.5 \%$ of individuals live in households reporting a monthly income less than $\$ 2,000$. Likewise, $79.3 \%$ of those in households earning more than $\$ 2,000$ monthly did not provide blood samples compared with $20.7 \%$ who did $(P=0.035)$ (Table 2).

Because pet ownership can be a marker for income, ${ }^{39,40}$ which appears to be associated with participation in our study, we also tested for an association between dog ownership and monthly household income, and found that among those with monthly household income less than $\$ 2,000,40.7 \%$ owned at least one dog, compared with $63.3 \%$ owning at least one dog among individuals with monthly household income greater than $\$ 2,000(P<0.001$, Table 2).

Strongyloides NIE-ELISA. Among the 92 households that participated in the survey, $43(46.7 \%)$ consented to blood sample collection. Within these 43 households, a total of 97 blood samples were collected from individuals aged between 2 years and older than 65 years (an additional three individuals consented to blood draws, but the nurse was unable to obtain a sample). Of the 97 blood samples tested, 16 (16.5\%) were seroreactive by ELISA for S. stercoralis at $100 \%$ sensitivity and $94.1 \%$ specificity (cutoff value $16.76 \mathrm{lgG}$ units $/ \mathrm{mL}$ via receiver operating characteristic curve). Of the 16 seroreactive cases, four (25\%) were detected in children ages 2 through 15 years, none of whom had traveled in the past 5 years. Of note, one $S$. stercoralis-seroreactive case was also detected in a pregnant woman.

Of the 16 seroreactive cases, four $(25 \%)$ reported a travel history to an endemic country outside of the United States in the past 5 years, roughly the same as the $21.3 \%$ that reported a travel history and had negative serology (Table 3). The remaining 12 (75\%) seroreactive cases were ostensibly acquired autochthonously. None of the children with positive serology were born outside of the United States.

Stool samples were obtained for 21/97 (21.6\%) participants who provided blood samples, and comparative stool qPCR was performed for only $7 / 16(43.8 \%)$ cases of positive

TABLE 1

Age and gender distribution of 92 surveyed households $(N=404)$

\begin{tabular}{lcrr}
\hline \multicolumn{1}{c}{ Age (years) } & Female, count $(\%)$ & Male, count (\%) & Total $(N=404)$, count (\%) \\
\hline$<2$ & $7(3.5)$ & $11(5.6)$ & $18(4.5)$ \\
Preschool, 2-5 & $15(7.5)$ & $16(8.1)$ & $31(7.8)$ \\
Prepuberty, 6-11 & $24(12.0)$ & $28(14.1)$ & $52(13.1)$ \\
Adolescent, 12-18 & $25(12.5)$ & $22(11.1)$ & $47(11.8)$ \\
Adult, $\geq 19$ & $129(64.5)$ & $121(61.1)$ & $250(62.8)$ \\
Total & $200(50.3)^{*}$ & $198(49.8)^{*}$ & $398^{*}$ \\
\hline
\end{tabular}

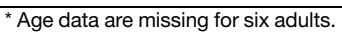




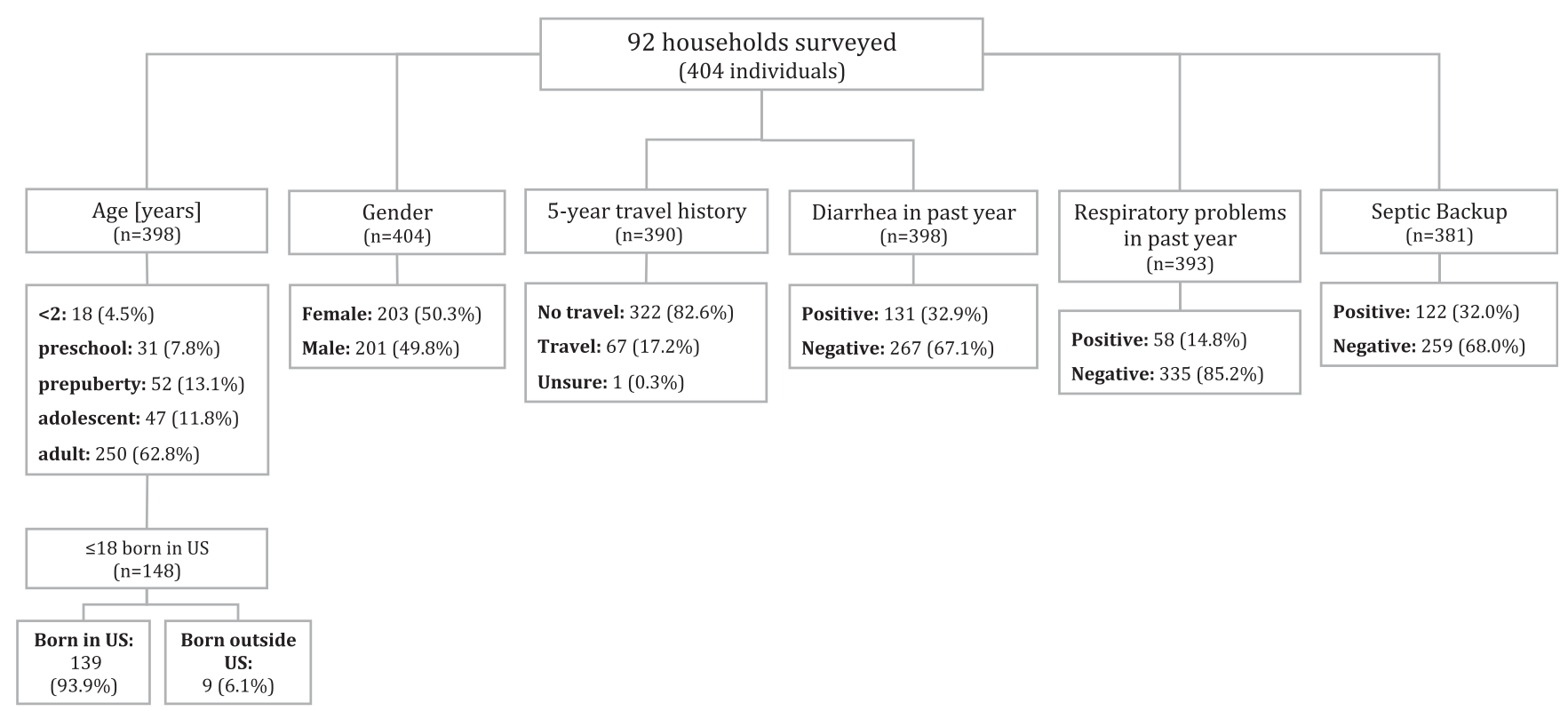

FIGURE 1. Study population characteristics.

S. stercoralis serology. None of these seven S. stercoralisseroreactive cases had a positive qPCR result for $S$. stercoralis.

Among individuals tested, the vast majority (92.5\%) of those residing in a household with monthly income greater than $\$ 2,000$ tested seronegative for $S$. stercoralis. In other words, there is a significant negative association between Strongyloides seropositivity and monthly household income greater than $\$ 2,000(P=0.011)$. Among those with negative serology, $62.8 \%$ have a monthly household income greater than $\$ 2,000$, whereas among those with positive serology, only a quarter comes from households with monthly income greater than $\$ 2,000$ (Table 3).

Strongyloides transmission is believed to commonly occur through skin penetration, such as walking barefoot in contaminated soil. Data about this behavior were collected for children ages 2 through 15 years, and in this small sample $(n=20)$, we cannot detect a significant association with positive serology (Table 3). Strongyloides stercoralis larval development and survival are affected by immersion in water; flooding may represent a significant factor in their survival and subsequent transmission to humans and animals. ${ }^{41,42}$ In this study, no significant difference in serology outcome was detected for flooding around the home. However, among those with negative serology, $74.1 \%$ reported flooding around their home, whereas the presence or absence of flooding was evenly split among those with positive serology (Table 3).

Multi-parallel real-time quantitative PCR. Only 43 of 404 $(10.6 \%)$ residents in the surveyed population submitted stool samples. Samples were tested by qPCR for nine species: A. lumbricoides, A. duodenale, N. americanus, S. stercoralis, T. trichiura, Blastocystis spp., Cryptosporidium spp., E. histolytica, and G. lamblia. All stool samples were negative for $A$. lumbricoides, $A$. duodenale, N. americanus, S. stercoralis, T. trichiura, Cryptosporidium spp., and $E$. histolytica. Of 43 stool samples received, 27 tested positive for Blastocystis (62.8\%), and one of these cases also tested positive for G. lamblia (2.3\%). None of the children with Blastocystis or G. lamblia were born outside of the United States. The child with $\mathrm{G}$. lamblia infection has no reported travel history within the past 5 years.

Blastocystis infection status is not significantly associated with monthly household income greater than $\$ 2,000(P=$ 1.000) among the 43 individuals tested (Table 4). In our study population, males were significantly more likely than females to be infected with Blastocystis $(66.7 \%$ male and $33.3 \%$ female, $P=0.032$, Table 4 ), as were those reporting diarrhea in the past year $(70.4 \%$ with diarrhea and $29.6 \%$ without diarrhea, $P=0.002$, Table 4). Males aged 6 through 11 years had the most Blastocystis

TABLE 2

Characteristics related to monthly household income $(N=391)$

\begin{tabular}{|c|c|c|c|}
\hline Characteristic & $\begin{array}{l}\text { Monthly household income } \\
<\$ 2,000(N=135[\%])\end{array}$ & $\begin{array}{l}\text { Monthly household income } \\
>\$ 2,000(N=256[\%])\end{array}$ & $P$-value \\
\hline \multicolumn{4}{|l|}{ Dog ownership } \\
\hline Yes $(n=217)$ & $55(40.7)$ & $162(63.3)$ & \multirow[t]{2}{*}{$<0.001^{\star \star \star}$} \\
\hline No $(n=174)$ & $80(59.3)$ & $94(36.7)$ & \\
\hline \multicolumn{4}{|c|}{ Provision of stool sample } \\
\hline Yes $(n=43)$ & $29(21.5)$ & $14(5.5)$ & \multirow{2}{*}{$<0.001^{\star \star \star}$} \\
\hline No $(n=348)$ & $106(78.5)$ & 242 (94.5) & \\
\hline \multicolumn{4}{|c|}{ Provision of blood sample } \\
\hline Yes $(n=94)$ & $41(30.4)$ & $53(20.7)$ & \multirow[t]{2}{*}{$0.035^{\star}$} \\
\hline No $(n=297)$ & 94 (69.6) & 203 (79.3) & \\
\hline
\end{tabular}


TABLE 3

Risk factor analysis for participants without relevant missing data and ELISA serum testing $(N=97)$

\begin{tabular}{|c|c|c|c|}
\hline Characteristic & $\begin{array}{c}\text { S. stercoralis-negative ELISA } \\
(n=81[83.5 \%])\end{array}$ & $\begin{array}{c}\text { S. stercoralis-positive ELISA } \\
(n=16[16.5 \%])\end{array}$ & $P$-value \\
\hline \multicolumn{4}{|l|}{ Gender } \\
\hline Male $(n=39)$ & $34(42.0)$ & 5 (31.3) & 0.579 \\
\hline Female $(n=58)$ & $47(58.0)$ & $11(68.8)$ & \\
\hline \multicolumn{4}{|l|}{ Monthly household income } \\
\hline$>\$ 2,000(n=53)$ & $49(62.8)$ & $4(25.0)$ & $0.011^{\star}$ \\
\hline$<\$ 2,000(n=41)$ & $29(37.2)$ & $12(75.0)$ & \\
\hline Travel history $(n=20)$ & $16(21.3)$ & $4(25.0)$ & 0.746 \\
\hline No travel history $(n=71)$ & $59(78.7)$ & $12(75.0)$ & \\
\hline Diarrheal history $(n=42)$ & $33(43.4)$ & 9 (56.3) & 0.414 \\
\hline No diarrhea $(n=50)$ & $43(56.6)$ & $7(43.8)$ & \\
\hline Respiratory history $(n=18)$ & $15(20.3)$ & $3(18.8)$ & 1.000 \\
\hline No respiratory history $(n=72)$ & 59 (79.7) & $13(81.3)$ & \\
\hline Dermatological history $(n=8)$ & $6(8.1)$ & $2(12.5)$ & 0.629 \\
\hline No dermatological history $(n=82)$ & $68(91.9)$ & $14(87.5)$ & \\
\hline Children barefoot outdoors $(n=14)$ & $12(70.6)$ & $2(66.7)$ & 1.000 \\
\hline Not barefoot $(n=6)$ & 5 (29.4) & 1 (33.3) & \\
\hline Dog(s) in household $(n=58)$ & $51(63.0)$ & $7(43.8)$ & 0.172 \\
\hline No dogs $(n=39)$ & $30(37.0)$ & $9(56.3)$ & \\
\hline Cat(s) $(n=15)$ & $12(14.8)$ & $3(18.8)$ & 0.709 \\
\hline No cats $(n=82)$ & 69 (85.2) & $13(81.3)$ & \\
\hline Goat(s) $(n=2)$ & $2(2.5)$ & 0 & 1.000 \\
\hline No goats $(n=95)$ & 79 (97.5) & $16(100.0)$ & \\
\hline Flooding around home $(n=68)$ & $60(74.1)$ & $8(50.0)$ & 0.074 \\
\hline No flooding $(n=29)$ & $21(25.9)$ & $8(50.0)$ & \\
\hline Septic backup $(n=40)$ & $35(43.8)$ & 5 (31.3) & 0.415 \\
\hline No septic backup $(n=56)$ & $45(56.3)$ & $11(68.8)$ & \\
\hline Toilet backup $(n=35)$ & 27 (33.3) & $8(50.0)$ & 0.257 \\
\hline No toilet backup $(n=62)$ & $54(66.7)$ & $8(50.0)$ & \\
\hline
\end{tabular}

S. stercoralis = Strongyloides stercoralis. Percentages are displayed in parentheses, adjusted to account for exclusion of cases with missing data where $n<97$. $P$-values are derived from Fisher's exact test. ${ }^{\star} P \leq 0.05$; ${ }^{\star \star} P \leq 0.01 ;{ }^{\star \star \star} P \leq 0.001$.

infections of any age-group, with $84.6 \%$ in that age-group testing positive.

Among individuals without Blastocystis, the households are approximately evenly split between having a dog and not, whereas among those with Blastocystis, the vast majority of individuals come from households that do not have a dog $(18.5 \%$ with dogs and $81.5 \%$ with no dogs, Table 4).

Among the 21 participants who provided both stool and blood samples, five (23.8\%) had positive laboratory findings suggestive of polyparasitism with $S$. stercoralis and Blastocystis spp. Stool Blastocystis DNA concentrations in positive

TABLE 4

Risk factor analysis for participants without relevant missing data and qPCR stool testing $(N=43)$

\begin{tabular}{lrr}
\hline \multicolumn{1}{c}{ Characteristic } & $\begin{array}{c}\text { Blastocystis negative } \\
(n=16[37.2 \%])\end{array}$ & $\begin{array}{c}\text { Blastocystis positive } \\
(n=27[62.8 \%])\end{array}$ \\
\hline Gender & & \\
$\quad$ Male $(n=23)$ & $5(31.3)$ & $18(66.7)$ \\
Female $(n=20)$ & $11(68.8)$ & $9(33.3)$ \\
Monthly household income & & $9(33.3)$ \\
$>\$ 2,000(n=14)$ & $5(31.3)$ & $18(66.7)$ \\
$<\$ 2,000(n=29)$ & $11(68.8)$ & $6(23.1)$ \\
Travel history $(n=9)$ & $3(18.8)$ & $20(76.9)$ \\
No travel history $(n=33)$ & $13(81.3)$ & $19(70.4)$ \\
Diarrheal history $(n=22)$ & $3(18.8)$ & $8(29.6)$ \\
No diarrhea $(n=21)$ & $13(81.3)$ & $3(12.0)$ \\
Dermatological history $(n=5)$ & $2(12.5)$ & $22(88.0)$ \\
No dermatological history $(n=36)$ & $14(87.5)$ & $5(18.5)$ \\
Dog(s) in household $(n=14)$ & $9(56.3)$ & $22(81.5)$ \\
No dogs $(n=29)$ & $7(43.8)$ & $6(22.2)$ \\
Cat(s) $(n=11)$ & $5(31.3)$ & $21(77.8)$ \\
No cats $(n=32)$ & $11(68.8)$ & $7(25.9)$ \\
Caged bird(s) $(n=9)$ & $2(12.5)$ & $20(74.1)$ \\
No caged birds $(n=34)$ & $14(87.5)$ & $14(51.9)$ \\
Flooding around home $(n=27)$ & $13(81.3)$ & $13(48.1)$ \\
No flooding $(n=16)$ & $3(18.8)$ & $7(25.9)$ \\
Septic backup $(n=11)$ & $4(25.0)$ & $20(74.1)$ \\
No septic backup $(n=32)$ & $12(75.0)$ & $12(44.4)$ \\
Toilet backup $(n=18)$ & $6(37.5)$ & $15(55.6)$ \\
No toilet backup $(n=25)$ & $10(62.5)$ & 1.000 \\
\hline Percentages are displayed in parentheses, adjusted to account for exclusion of cases with missing data where $n<43 . P$-values are derived from Fisher's exact test. ${ }^{*} P \leq 0.05 ;{ }^{* *} P \leq 0.01 ;$
\end{tabular}


samples ranged from 0.0041 to $598,962.1 \mathrm{fg} / \mu \mathrm{L}$, with a mean of $42,711.8 \mathrm{fg} / \mu \mathrm{L}$.

\section{DISCUSSION}

Among members of this central Texas community who participated in our study, we found that $16.5 \%$ were seroreactive for S. stercoralis, $62.8 \%$ tested positive for Blastocystis spp., and $2.3 \%$ tested positive for G. lamblia.

Strongyloides. The prevalence of blood samples seroreactive for $S$. stercoralis in our sample is $16.5 \%$. The highest prevalence of $S$. stercoralis recorded in high-quality historic studies of soil-transmitted helminths in the United States approached $4 \%$, although this is considered an underestimate because of methodological limitations of the time. ${ }^{18,43}$ More recently, S. stercoralis antibody prevalence approached $2 \%$ in a seroprevalence study in rural Kentucky, ${ }^{22}$ and a $5 \%$ prevalence was detected via combined serology and qPCR in a study of immigrants from Latin America residing in Washington $\mathrm{DC}^{36}$ In rural Alabama, stool qPCR detected S. stercoralis in $7.3 \%$ of residents tested. ${ }^{24}$ Among a cohort of AIDS patients from a U.S. urban center, $25 \%$ were seropositive for $S$. stercoralis, most of whom had emigrated from known endemic areas ${ }^{38}-S$. stercoralis prevalence in the United States is generally higher among immigrants and refugees as well as travelers and veterans returning from endemic areas. ${ }^{43-46}$ Strongyloidiasis has also historically been found to be more prevalent among institutionalized persons in the United States. ${ }^{47-49}$ Globally, S. stercoralis prevalence estimates and corresponding data are heterogeneous, using incomparable varying diagnostic techniques. ${ }^{43,50}$ Existing, mixed-quality data suggest rates between $10 \%$ and $40 \%$ of populations are infected with $S$. stercoralis in many tropical and subtropical countries. ${ }^{50}$

Although stool samples were available for only $7 / 16$ (43.8\%) cases of positive $S$. stercoralis serology, none of the seven stool samples from individuals with chronic strongyloidiasis had positive qPCR for S. stercoralis-this discrepancy may reflect cleared infection and a previous history of strongyloidiasis or may also be a product of parasite biology_parasite load is often low, and larval output is irregular. ${ }^{51}$ Other studies document a similar discrepancy between stool and serology testing for Strongyloides. ${ }^{45,52-54}$ Given the presence of stray dogs and other animals in this area, the possibility remains that human toxocariasis, a zoonotic helminthiasis, is also prevalent, and the sera from some of our study participants may have crossreacted to Toxocara spp. However, recent studies on the Strongyloides NIE-ELISA IgG find that it exhibits high specificity, ranging from $90.7 \%$ to $98.9 \%$, in one study ${ }^{55}$ to $100 \%$ in another study, ${ }^{36}$ reducing the likelihood of this possibility.

Because of the nematode's autoinfection cycle, which, without adequate treatment, results in decades-long or lifetime infections in human hosts, chronic and latent Strongyloides infection can become life-threatening through hyperinfection and/or dissemination syndromes. ${ }^{14,43,46,56-58}$ Strongyloidiasis hyperinfection has resulted in mortality in up to $87 \%$ of reported cases. ${ }^{43}$ A population-based case-control study using mortality data from 1991 to 2006 found that deaths from strongyloidiasis were reported from 36 of the 50 states, with most $(62.3 \%)$ deaths among persons born in the United States. ${ }^{14}$

As for the other soil-transmitted helminths, Strongyloides is a severely under-recognized public health threat in North
America. ${ }^{56-58}$ Both public and clinical awareness of the risk of Strongyloides infection are lacking, in human and veterinary medicine. ${ }^{56}$ Jariwala et al. argue for a "One Health" approach to the public health threat posed by the parasite, given that zoonotic and environmental factors are critical in Strongyloides epidemiology. ${ }^{56}$ The role of canines in Strongyloides transmission in Community $A$ is uncertain but merits further investigation.

The seriousness of infection with Strongyloides cannot be overstated, especially in the U.S. clinical context. Disseminated strongyloidiasis is unique in that mortality in the United States is nearly always iatrogenic; especially in the case of patients taking steroids with chronic Strongyloides infection, fatal hyperinfection can result, with mortality frequently owing to Gram-negative sepsis. ${ }^{58}$ In their survey of U.S. residentphysicians, Boulware et al. found that U.S. physicians-intraining had poor recognition $(9 \%)$ of the need for parasite screening generally and frequently prescribed empiric corticosteroids (23\%). ${ }^{58}$ In comparison, $56 \%$ of international trainees recognized the need for parasite screening $(P<$ $0.001) ; 41 \%$ of U.S. physicians were unable to choose any parasite causing pulmonary symptoms. ${ }^{58}$

Blastocystis. The prevalence of Blastocystis, a heterokont parasite transmitted via the fecal-oral route, in our sample is $62.8 \%$. The highest prevalence of Blastocystis ever observed worldwide was $100 \%$ in a population of Senegalese children. ${ }^{59}$ Blastocystis prevalence among the general population of industrialized countries often exceeds $5 \%$ and can approach $30-60 \%$ in developing countries. ${ }^{60}$ Several epidemiological surveys from different countries identify Blastocystis spp. as the most common eukaryotic parasite detected in human fecal samples, ${ }^{61}$ and, as in our study, its prevalence is overall higher than the prevalence of other intestinal protozoan parasites including Giardia, Entamoeba, and Cryptosporidium ${ }^{62,63}-2.3 \%$ of our samples contained Giardia and the latter two protozoa were not detected in any of our stool samples. In a study of intestinal infections in residents of the U.S. Rocky Mountain region, Blastocystis sp. was the most frequently detected species, at about $4 \%$ prevalence year-round. ${ }^{64}$ Nationally, annual prevalence of Blastocystis in the United States declined from $23 \%$ in 2000 to $11 \%$ in 2004 , when the last large-scale investigation was conducted. ${ }^{65}$ From 2002 to 2004, the estimated prevalence of Blastocystis infection in Texas was $7 \% .{ }^{65}$ At $62.8 \%$, the prevalence of this parasite among study participants living in Community $A$ is uncharacteristically high for a developed country and for the state of Texas alike and underscores a substantial degree of ongoing environmental contamination with sewage.

The pathogenicity of Blastocystis is thought to be related to specific subtypes and parasite burden, although even individuals harboring a small number of cysts can be symptomatic. ${ }^{66}$ Some clinicians recommend that individuals with low parasite burden and no symptoms not be treated, although those with gastrointestinal or dermatologic signs and symptoms and high parasite burden may require treatment. ${ }^{66}$

Although other studies have also identified an increased risk for males to harbor Blastocystis, ${ }^{67-69}$ there are many studies that did not find a significant association with gender. ${ }^{70-76}$ In accordance with societal gender biases, it has been suggested that males are at increased risk for Blastocystis because of their increased participation in outdoor activities, which heightens the likelihood of fecal-oral transmission in 
environments where the parasite is present. During fieldwork in Community A, male children were more frequently observed playing outside than were female children, but this was not objectively measured.

Of note, Community A has a large population of stray dogs, which often respect no lot boundaries, meaning that households that do not own a dog may still have dog feces in their yard. This issue blurs the association between dog ownership, dog feces exposure, and Blastocystis infection rates. Although our results suggest a negative association between dog ownership and Blastocystis infection, this finding may be related to our sampling strategy, which, for safety reasons, excluded households with apparently aggressive dogs, barring communication to gauge resident interest in participation. The association with income may also partly explain our finding that having a dog in Community A is negatively associated with Blastocystis infection. No other pets were identified as significantly associated with Blastocystis infection. Contrary to our findings, dog ownership and/or living in close proximity to other domestic animals or pets was identified as a risk factor for Blastocystis infection in other studies. ${ }^{74,77,78}$ Future investigation of canine fecal studies and seroprevalence may be informative, as both stray and domesticated dogs are omnipresent throughout the community and have been implicated in zoonotic transmission pathways for both protozoan and helminthic parasites. ${ }^{56,79-84}$

Blastocystis is transmitted via fecal-oral infection route, by which humans become infected through environmental contamination. Given the extent of septic failure, it is likely that human sewage is responsible for the increased prevalence of intestinal parasites in this sample. Problems with septic systems are widespread in Community $A$, and an analysis of soil types may provide an explanation. A 2018 United States Department of Agriculture soil map obtained for the area clearly identifies more than two-thirds of the community rests on soil types that are not compatible with septic systems because of very slow permeability, rendering the septic systems susceptible to clogging. ${ }^{85}$

Clinical implications. Limited knowledge of helminths by U.S. clinicians puts a large population of both immigrant and U.S.-born Americans in iatrogenic danger. Clinical suspicion for and awareness of neglected intestinal parasites may be improved with an emphasis on these infections in U.S. medical training and continuing medical education. ${ }^{58}$ Boulware et al. ${ }^{58}$ suggest that although it may be unrealistic to expect comprehensive helminth knowledge among U.S. physicians, basic knowledge of iatrogenic danger posed by corticosteroids and Strongyloides infection should exist. Clinical suspicion in both practice and laboratory settings may additionally be enhanced by mandatory reporting of Strongyloides and other helminths. However, in 2016, Texas became the first state to mandate reporting of ascariasis, trichuriasis, and hookworm infection with the passage of 2015 H.B. 2055, an act relating to the establishment of a sentinel surveillance program for emerging and neglected tropical diseases, in which strongyloidiasis was excluded from the list of notifiable conditions. ${ }^{86}$ None of the soil-transmitted helminths are nationally notifiable. ${ }^{87}$

Policy implications. Several policy implications arise from our findings of high rates of Blastocystis- and Strongyloidespositive laboratory findings in central Texas. First, as suggested earlier, strongyloidiasis should be added to the Texas notifiable conditions list at the next annual update. Likewise, strongyloidiasis and the other endemic soil-transmitted helminths should be added to the list of nationally notifiable diseases, which is reviewed and updated annually by the Council of State and Territorial Epidemiologists and the CDC. ${ }^{87}$

Second, given the lack of familiarity and awareness for strongyloidiasis among U.S.-trained clinicians, state and national medical associations should highlight neglected parasitic infections in their campaigns and activities in their provision of continuing medical education. An emphasis should be placed on updated regional findings as well as vulnerable populations, with health departments alerting clinicians and laboratories to the most recent epidemiological findings in an effort to heighten clinical suspicion and capacity to treat. The U.S. medical community can benefit from the lessons learned by developing countries with more experience with strongyloidiasis prevention and control.

Third, health departments should collaborate with other local, state, and federal resources to address the underlying equity issues promoting these health disparities, with an aim toward prevention. Findings such as a prevalence rate for Blastocystis on par with developing countries underscore that at least one American community suffers substantially from lack of access to functioning sanitation infrastructure-as such, its residents are denied that basic human right and public health is jeopardized. Based on widespread economic and infrastructure disparities, there are likely many more Americans facing similar realities nationwide.

Community A shares commonalities with the bettercharacterized peri-urban unincorporated communities along the Texas-Mexico border, often referred to as colonias or urban slums. A growing body of research suggests that the annexation and incorporation of these communities can drive the evolution of improved infrastructure access across energy, water, and wastewater systems, ${ }^{88}$ and that residents experience improved standards of living owing to municipal oversight. ${ }^{89}$ However, Durst demonstrates a systematic failure of cities to annex surrounding minority communities, with cities selectively under-bounding census blocks that contain colonias, especially those containing colonias with poor infrastructure. ${ }^{89}$ Despite the introduction by the Texas legislature of Subchapter B of Chapter 232, Local Government Code, in 1995, which intended to promote the upgrading of critical infrastructure in southern Texas colonias, decades later, there are heterogeneous impacts of this policy on built environment parameters regionally. As Guerra Uribe et al. argue, decision-makers should focus on localized efforts within the broader existing policy context to increase services access, highlighting the need for tailoring solutions to the county and city level. ${ }^{88}$ Community $A$ residents will need to determine the most amenable path forward in addressing their wastewater infrastructure, given their local cultural, financial, and jurisdictional constraints.

Limitations. The sample is representative of those who provided stool and/or blood samples from the surveyed households in Community A. Although our sampling strategy made a systematic attempt to include all households, we do observe a degree of participation bias. The relationships between monthly household income and provision of stool and blood samples suggest a systematic oversampling of lower income residents, although income has not been standardized for household size. Possible reasons for this type of 
sampling bias may be that higher income households were less accessible to research personnel during study recruitment because of gated properties, and that participants were offered $\$ 15$ compensation for completing the survey and for later providing stool and/or blood samples.

In the case of some analyses, the sample used to test for an association between a given risk factor and positive laboratory finding was quite small. Fisher's exact test is designed to accommodate small samples and is considered a conservative statistical test. However, because of reduced statistical power, lack of statistical significance cannot be interpreted as the absence of an association. In addition, clustering by household (where cases come from the same household) may influence the risk of infection transmission. The small number of stool and blood samples obtained precludes a meaningful multiple regression analysis by household cluster. The significant association between low income and S. stercoralis seropositivity is supported by prior work documenting this parasite in conditions of poverty and poor sanitation and hygiene. ${ }^{43,49,50}$

\section{CONCLUSION}

This pilot active surveillance study demonstrates the presence of neglected intestinal parasites in a Texas community and adds to the weight of evidence demonstrating the burden of neglected intestinal parasites in the United States. Effective and sustainable public health programming will depend on accurate prevalence estimation as well as public willingness and support for addressing health disparities. To aid research and public health communities in focusing surveillance efforts on the most at-risk U.S. populations, we are developing species distribution models for strongyloidiasis and other soil-transmitted helminths so that resources may be efficiently directed. Moreover, the public health information these studies generate could be used for community-driven decision support initiatives to help secure effective sanitation and protection from preventable diseases.

Received December 9, 2019. Accepted for publication February 9, 2020.

Published online March 23, 2020.

Acknowledgments: Data collection in the field was carried out by R. S. and the following University of Texas at Austin students (alphabetical order): Felipe Araya Araya, Kelsea Auguillard, Emily Baysden, Sara Becker, Carlos Lopez Bray, Catherine Cruz, Jessica Ellis, Bibiana Toro Figueira, Laney Hempel, Eric Johnson, Shreya Mallena, Monica Navarro-Jimenez, Chelsea Nguyen, Ebubechukwu Okeke, Camila Peterson, Eleonore Saliba, and Ressiel Nicole Villegas. We thank Kerry Kinney and Juan-Pedro Maestre for their advice and for generously providing sample storage space in BSL-2 laboratory. Stephanie Borjas, RN, performed phlebotomy. Anthropometric equipment was generously loaned from the University of Texas Health Science Center at Houston School of Public Health in Austin.

Financial support: Funds for participant compensation were generously provided by the LBJ School of Public Affairs. Funds for the phlebotomy portion were generously provided via the Doctoral Dissertation Grant Program of the Fahs-Beck Fund for Research and Experimentation, a fund established with the New York Community Trust. Research funding support for R. M. was provided by the U.S. Department of Health and Human Services, Health Resources and Services Administration for Baylor College of Medicine Center of Excellence in Health Equity, Training and Research (Grant
No: D34HP31024). Funding was also provided by the Texas Children's Hospital Center for Vaccine Development, and the National School of Tropical Medicine, Baylor College of Medicine.

Disclosures: R. M. receives research funding from Romark Laboratories, LC. This association did not impact this study.

Authors' addresses: Rachael Singer and Abigail R. A. Aiken, Lyndon B. Johnson School of Public Affairs, The University of Texas at Austin, Austin, TX, E-mails: rsinger@utexas.edu and araa2@utexas.edu. Teena Huan Xu, Lauren Nicholas S. Herrera, Maria Jose Villar, Peter J. Hotez, and Rojelio Mejia, Department of Pediatrics: Tropical Medicine, National School of Tropical Medicine, Baylor College of Medicine, Houston, TX, E-mails: huan.xu@bcm.edu, lauren. herrera@bcm.edu, mariajose.villarmondragon@bcm.edu, hotez@ bcm.edu, and rojelio.mejia@bcm.edu. Kasey M. Faust, Department of Civil, Architectural and Environmental Engineering, The University of Texas at Austin, Austin, TX, E-mail: faustk@utexas.edu.

\section{REFERENCES}

1. Nokes C, Grantham-McGregor SM, Sawyer AW, Cooper ES, Bundy DA, 1992. Parasitic helminth infection and cognitive function in school children. Proc Biol Sci 247: 77-81.

2. Nguyen NL, Gelaye B, Aboset N, Kumie A, Williams MA, Berhane $\mathrm{Y}$, 2012. Intestinal parasitic infection and nutritional status among school children in Angolela, Ethiopia. J Prev Med Hyg 53: 157-164.

3. Simsek Z, Zeyrek FY, Kurcer MA, 2004. Effect of Giardia infection on growth and psychomotor development of children aged 0-5 years. J Trop Pediatr 50: 90-93.

4. Yentur Doni N, Yildiz Zeyrek F, Simsek Z, Gurses G, Sahin I, 2015. Risk factors and relationship between intestinal parasites and the growth retardation and psychomotor development delays of children in Şanlıurfa, Turkey. Turk Parazitolojii Derg 39: 270-276.

5. LaBeaud AD et al., 2015. Parasitism in children aged three years and under: relationship between infection and growth in rural coastal Kenya. PLoS Negl Trop Dis 9: e0003721.

6. Ezeamama AE, Friedman JF, Acosta LP, Bellinger DC, Langdon GC, Manalo DL, Olveda RM, Kurtis JD, McGarvey ST, 2005. Helminth infection and cognitive impairment among Filipino children. Am J Trop Med Hyg 72: 540-548.

7. Sakti H, Nokes C, Hertanto WS, Hendratno S, Hall A, Bundy DA, Satoto, 1999. Evidence for an association between hookworm infection and cognitive function in Indonesian school children. Trop Med Int Health 4: 322-334.

8. Miguel E, Kremer M, 2004. Worms: identifying impacts on education and health in the presence of treatment externalities. Econometrica 72: 159-217.

9. Pabalan N, Singian E, Tabangay L, Jarjanazi H, Boivin MJ, Ezeamama AE, 2018. Soil-transmitted helminth infection, loss of education and cognitive impairment in school-aged children: a systematic review and meta-analysis. PLoS Negl Trop Dis 12: e0005523.

10. Bleakley $H, 2007$. Disease and development: evidence from hookworm eradication in the American south. $Q J$ Econ 122: 73-117.

11. Alva $A$, Cangalaya $C$, Quiliano $M$, Krebs $C$, Gilman $R H$, Sheen $P$, Zimic M, 2017. Mathematical algorithm for the automatic recognition of intestinal parasites. PLoS One 12: e0175646.

12. Taniuchi M, Verweij JJ, Noor Z, Sobuz SU, van Lieshout L, Petri WA, Haque R, Houpt ER, 2011. High throughput multiplex PCR and probe-based detection with luminex beads for seven intestinal parasites. Am J Trop Med Hyg 84: 332-337.

13. Maskery B, Coleman MS, Weinberg M, Zhou W, Rotz L, Klosovsky A, Cantey PT, Fox LM, Cetron MS, Stauffer WM, 2016. Economic analysis of the impact of overseas and domestic treatment and screening options for intestinal helminth infection among US-bound refugees from Asia. PLoS Negl Trop Dis 10: e0004910.

14. Croker C, Reporter R, Redelings M, Mascola L, 2010. Strongyloidiasisrelated deaths in the United States, 1991-2006. Am J Trop Med Hyg 83: 422-426. 
15. Mejia R, Vicuña $Y$, Broncano N, Sandoval C, Vaca M, Chico M, Cooper PJ, Nutman TB, 2013. A novel, multi-parallel, real-time polymerase chain reaction approach for eight gastrointestinal parasites provides improved diagnostic capabilities to resource-limited at-risk populations. Am J Trop Med Hyg 88: 1041-1047.

16. Montes M, Sawhney C, Barros N, 2010. Strongyloides stercoralis: there but not seen. Curr Opin Infect Dis 23: 500-504.

17. Booker CA, 2019. S.2675-116th Congress (2019-2020): Study, Treat, Observe, and Prevent Neglected Diseases of Poverty Act. Available at: https://www.congress.gov/bill/116th-congress/ senate-bill/2675. Accessed December 6, 2019.

18. Starr MC, Montgomery SP, 2011. Soil-transmitted helminthiasis in the United States: a systematic review-1940-2010. Am J Trop Med Hyg 85: 680-684.

19. Office of the Commission, 1915. Fifth Annual Report for the Year 1914, The Rockefeller Sanitary Commission for the Eradication of Hookworm Disease. Washington, DC: Rockefeller Sanitary Commission for the Eradication of Hookworm Disease. Available at: http://www.archive.org/details/cu31924005710839. Accessed December 6, 2019.

20. Smith WH, McAlpine JG, Gill DG, 1937. Intestinal parasite survey in Alabama-I. A comparative study of two hookworm anthelmintics. Am J Public Health Nations Health 27: 471-475.

21. Hosty TS, Wells DM, Freear MA, Whitfield NK, 1954. Hookworm in Alabama. J Med Assoc State Ala 23: 179-182.

22. Russell ES, Gray EB, Marshall RE, Davis S, Beaudoin A, Handali S, McAuliffe I, Davis C, Woodhall D, 2014. Prevalence of Strongyloides stercoralis antibodies among a rural Appalachian population-Kentucky, 2013. Am J Trop Med Hyg 91: 1000-1001.

23. Croker $C$, She R, 2015. Notes from the field: increase in reports of Strongyloides infection-Los Angeles county, 2013-2014. US Cent Dis Control Prev 64: 922-923.

24. McKenna ML, McAtee S, Bryan PE, Jeun R, Ward T, Kraus J, Bottazzi ME, Hotez PJ, Flowers CC, Mejia R, 2017. Human intestinal parasite burden and poor sanitation in rural Alabama. Am J Trop Med Hyg 97: 1623-1628.

25. Strunz EC, Addiss DG, Stocks ME, Ogden S, Utzinger J, Freeman MC, 2014. Water, sanitation, hygiene, and soil-transmitted helminth infection: a systematic review and meta-analysis. PLoS Med 11: e1001620.

26. Shaefer HL, Edin K, 2013. Rising extreme poverty in the United States and the response of federal means-tested transfer programs. Soc Serv Rev 87: 250-268.

27. Shaefer HL, Edin K, Talbert E, 2015. Understanding the dynamics of \$2-a-day poverty in the United States. RSF Russell Sage Found J Soc Sci 1: 120-138.

28. U.S. Census Bureau, 2018. Physical Housing Characteristics for Occupied Housing Units (S2504); Selected Housing Characteristics (DP04) 2013-2017 American Community Survey 5-Year Estimates. Available at: https://data.census.gov/cedsci/ table?q=S25\&d=ACS\%201-Year\%20Estimates\%20Subject\% 20Tables\&table=S2504\&tid=ACSST1Y2018.S2504\&lastDisplayed Row=25. Accessed September 21, 2019.

29. U.S. Census Bureau, 2017. National-Plumbing, Water, and Sewage Disposal-All Occupied Units, American Housing Survey. Available at: https://www.census.gov/programs-surveys/ ahs/data/interactive/ahstablecreator.html?s_areas $=00000 \&$ s year=2017\&s_tablename=TABLE4\&s_bygroup1=1\&s_bygroup2= 1\&s_filtergroup1=1\&s_filtergroup2=1. Accessed September 21, 2019.

30. Verrecchia J, 2018. The feasibility of septic systems for households in poverty in Lee county, Virginia. J Appalach Stud 24: 223-235.

31. Jepson W, Vandewalle E, 2016. Household water insecurity in the global north: a study of rural and Periurban settlements on the Texas-Mexico border. Prof Geogr 68: 66-81.

32. McDonald YJ, Grineski SE, 2012. Disparities in access to residential plumbing: a binational comparison of environmental injustice in El Paso and Ciudad Juarez. Popul Environ 34: 194-216.

33. Korc ME, Ford PB, 2013. Application of the water poverty index in border colonias of west Texas. Water Policy 15: 79-97.
34. Harris PA, Taylor R, Thielke R, Payne J, Gonzalez N, Conde JG, 2009. Research electronic data capture (REDCap)-a metadatadriven methodology and workflow process for providing translational research informatics support. J Biomed Inform 42: 377-381.

35. Cimino RO, Jeun R, Juarez M, Cajal PS, Vargas P, Echazú A, Bryan PE, Nasser J, Krolewiecki A, Mejia R, 2015. Identification of human intestinal parasites affecting an asymptomatic peri-urban Argentinian population using multi-parallel quantitative real-time polymerase chain reaction. Parasit Vectors 8: 380.

36. Ostera G, Blum J, Cornejo C, Burgula S, Jeun R, Bryan PE, Mejia $\mathrm{R}, 2017$. Strongyloidiasis in Latin American immigrants: a pilot study. J Helminthol 91: 262-266.

37. Poirier P, Wawrzyniak I, Albert A, El Alaoui H, Delbac F, Livrelli V, 2011. Development and evaluation of a real-time PCR assay for detection and quantification of Blastocystis parasites in human stool samples: prospective study of patients with hematological malignancies. J Clin Microbiol 49: 975-983.

38. Nabha L, Krishnan S, Ramanathan R, Mejia R, Roby G, Sheikh V, McAuliffe I, Nutman T, Sereti I, 2012. Prevalence of Strongyloides stercoralis in an urban US AIDS cohort. Pathog Glob Health 106: 238-244.

39. Teclaw R, Mendlein J, Garbe P, Mariolis P, 1992. Characteristics of pet populations and households in the Purdue comparative oncology program catchment area, 1988. J Am Vet Med Assoc 201: 1725-1729.

40. Martins CM, Mohamed A, Guimarães AM, de Barros Cda C, Pampuch Rdos S, Svoboda W, Garcia Rde C, Ferreira F, Biondo AW, 2013. Impact of demographic characteristics in pet ownership: modeling animal count according to owners income and age. Prev Vet Med 109: 213-218.

41. Forrer A, Khieu V, Vounatsou P, Sithithaworn P, Ruantip S, Huy R, Muth S, Odermatt P, 2019. Strongyloides stercoralis: spatial distribution of a highly prevalent and ubiquitous soiltransmitted helminth in Cambodia. PLoS Negl Trop Dis 13: e0006943.

42. Anamnart W, Pattanawongsa A, Intapan PM, Morakote N, Janwan P, Maleewong W, 2013. Detrimental effect of water submersion of stools on development of Strongyloides stercoralis. PLoS One 8: e82339.

43. Genta RM, 1989. Global prevalence of strongyloidiasis: critical review with epidemiologic insights into the prevention of disseminated disease. Rev Infect Dis 11: 755-767.

44. Keystone JS, 2007. Can one afford not to screen for parasites in high-risk immigrant populations? Clin Infect Dis 45: 1316-1318.

45. Akiyama MJ, Brown JD, 2018. Human strongyloidiasis in Hawaii: a retrospective review of enzyme-linked immunosorbent assay serodiagnostic testing. Am J Trop Med Hyg 99: 370-374.

46. Newberry AM, Williams DN, Stauffer WM, Boulware DR, HendelPaterson BR, Walker PF, 2005. Strongyloides hyperinfection presenting as acute respiratory failure and gram-negative sepsis. Chest 128: 3681-3684.

47. Jeffery GM, 1960. A three-year epidemiologic study of intestinal parasites in a selected group of mental patients. Am J Hyg 71: 1-8.

48. Nair D, 2001. Screening for Strongyloides infection among the institutionalized mentally disabled. J Am Board Fam Pract 14: 51-53.

49. Yoeli M, Most H, Hammond J, Scheinesson GP, 1972. Parasitic infections in a closed community. Trans $R$ Soc Trop Med Hyg 66: 764-776.

50. Schär F, Trostdorf U, Giardina F, Khieu V, Muth $S$, Marti $H$, Vounatsou P, Odermatt P, 2013. Strongyloides stercoralis: global distribution and risk factors. PLoS Negl Trop Dis 7: e2288.

51. Siddiqui AA, Berk SL, 2001. Diagnosis of Strongyloides stercoralis infection. Clin Infect Dis Off Publ Infect Dis Soc Am 33: 1040-1047.

52. Chang AH, Perry S, Du JNT, Agunbiade A, Polesky A, Parsonnet J, 2013. Decreasing intestinal parasites in recent Northern California refugees. Am J Trop Med Hyg 88: 191-197.

53. Formenti F, La Marca G, Perandin F, Pajola B, Romano M, Santucci B, Silva R, Giorli G, Bisoffi Z, Buonfrate D, 2019. A diagnostic study comparing conventional and real-time PCR 
for Strongyloides stercoralis on urine and on faecal samples. Acta Trop 190: 284-287.

54. Yori PP et al., 2006. Seroepidemiology of strongyloidiasis in the Peruvian Amazon. Am J Trop Med Hyg 74: 97-102.

55. Bisoffi $Z$ et al., 2014. Diagnostic accuracy of five serologic tests for Strongyloides stercoralis infection. PLoS Negl Trop Dis 8: e2640.

56. Jariwala S, Redding L, Hewitt D, 2017. The severely underrecognized public health risk of strongyloidiasis in North American cities-a one health approach. Zoonoses Public Health 64: 579-588.

57. Bisoffi $Z$ et al., 2013. Strongyloides stercoralis: a plea for action. PLoS Negl Trop Dis 7: e2214.

58. Boulware DR, Stauffer WM, Hendel-Paterson BR, Rocha JLL, Seet RC-S, Summer AP, Nield LS, Supparatpinyo K, Chaiwarith $\mathrm{R}$, Walker PF, 2007. Maltreatment of Strongyloides infection: case series and worldwide physicians-in-training survey. Am J Med 120: 545.e1-545.e8.

59. El Safadi D et al., 2014. Children of Senegal River Basin show the highest prevalence of Blastocystis sp. ever observed worldwide. BMC Infect Dis 14: 164.

60. Wawrzyniak I, Poirier P, Viscogliosi E, Dionigia M, Texier C, Delbac F, Alaoui HE, 2013. Blastocystis, an unrecognized parasite: an overview of pathogenesis and diagnosis. Ther Adv Infect Dis 1: 167-178.

61. Tan KS, 2008. New insights on classification, identification, and clinical relevance of Blastocystis spp. Clin Microbiol Rev 21: 639-665.

62. ANOFEL Cryptosporidium National Network, 2010. Laboratorybased surveillance for Cryptosporidium in France, 2006-2009. Euro Surveill Bull Eur Sur Mal Transm Eur Commun Dis Bull 15: 19642.

63. Boorom KF et al., 2008. Oh my aching gut: irritable bowel syndrome, Blastocystis, and asymptomatic infection. Parasit Vectors 1: 40.

64. Church C, Neill A, Schotthoefer AM, 2010. Intestinal infections in humans in the Rocky Mountain region, United States. J Parasitol 96: 194-196.

65. Amin OM, 2006. The epidemiology of Blastocystis hominis in the United States. Res J Paras 1: 1-10.

66. Coyle CM, Varughese J, Weiss LM, Tanowitz HB, 2012. Blastocystis: to treat or not to treat. Clin Infect Dis Off Publ Infect Dis Soc Am 54: 105-110.

67. Abdulsalam AM, Ithoi I, Al-Mekhlafi HM, Khan AH, Ahmed A, Surin J, Mak JW, 2013. Prevalence, predictors and clinical significance of Blastocystis sp. in Sebha, Libya. Parasit Vectors 6: 86.

68. Al-Fellani MA, Khan AH, Al-Gazoui RM, Zaid MK, Al-Ferjani MA, 2007. Prevalence and clinical features of Blastocystis hominis infection among patients in Sebha, Libya. Sultan Qaboos Univ Med J 7: 35-40.

69. Leder K, Hellard ME, Sinclair MI, Fairley CK, Wolfe R, 2005. No correlation between clinical symptoms and Blastocystis hominis in immunocompetent individuals. J Gastroenterol Hepatol 20: $1390-1394$.

70. Khoshnood S, Rafiei A, Saki J, Alizadeh K, 2015. Prevalence and genotype characterization of Blastocystis hominis among the Baghmalek people in southwestern Iran in 2013-2014. Jundishapur J Microbiol 8: e23930.

71. Seyer A, Karasartova D, Ruh E, Güreser AS, Turgal E, Imir T, Taylan-Ozkan A, 2017. Epidemiology and prevalence of Blastocystis spp. in North Cyprus. Am J Trop Med Hyg 96: 1164-1170.

72. Salehi R, Haghighi A, Stensvold CR, Kheirandish F, Azargashb E, Raeghi S, Kohansal C, Bahrami F, 2017. Prevalence and subtype identification of Blastocystis isolated from humans in
Ahvaz, southwestern Iran. Gastroenterol Hepatol Bed Bench 10: $235-241$.

73. Rezaei Riabi T, Haghighi A, Mirjalali H, Mohammad Ali Gol S, Karamati SA, Ghasemian M, Bahadori Monfared A, Aghamohammadi E, Zojaji H, 2017. Study of prevalence, distribution and clinical significance of Blastocystis isolated from two medical centers in Iran. Gastroenterol Hepatol Bed Bench 10 (Suppl 1): S102-S107.

74. Belleza MLB, Cadacio JLC, Borja MP, Solon JAA, Padilla MA, Tongol-Rivera PN, Rivera WL, 2015. Epidemiologic study of Blastocystis infection in an urban community in the Philippines. J Environ Public Health 2015: 894297.

75. Abu-Madi M, Aly M, Behnke JM, Clark CG, Balkhy H, 2015. The distribution of Blastocystis subtypes in isolates from Qatar. Parasit Vectors 8: 465.

76. Beyhan YE, Yilmaz H, Cengiz ZT, Ekici A, 2015. Clinical significance and prevalence of Blastocystis hominis in Van, Turkey. Saudi Med J 36: 1118-1121.

77. Forson AO, Arthur I, Olu-Taiwo M, Glover KK, Pappoe-Ashong PJ, Ayeh-Kumi PF, 2017. Intestinal parasitic infections and risk factors: a cross-sectional survey of some school children in a suburb in Accra, Ghana. BMC Res Notes 10: 485.

78. Rajah Salim H, Suresh Kumar G, Vellayan S, Mak JW, Khairul Anuar A, Init I, Vennila GD, Saminathan R, Ramakrishnan K, 1999. Blastocystis in animal handlers. Parasitol Res 85: 1032-1033.

79. Puebla LEJ, Núñez FA, Rivero LR, Hernández YR, Millán IA, Müller $\mathrm{N}, 2017$. Prevalence of intestinal parasites and molecular characterization of Giardia duodenalis from dogs in La Habana, Cuba. Vet Parasitol Reg Stud Rep 8: 107-112.

80. Basso W, Grandt L-M, Magnenat A-L, Gottstein B, Campos M, 2019. Strongyloides stercoralis infection in imported and local dogs in Switzerland: from clinics to molecular genetics. Parasitol Res 118: 255-266.

81. Godínez-Galaz EM, Veyna-Salazar NP, Olvera-Ramírez AM, Milián-Suazo F, Perea-Razo CA, Bernal-Reynaga R, CantóAlarcón GJ, 2019. Prevalence and zoonotic potential of Giardia intestinalis in dogs of the central region of Mexico. Animals (Basel) 9: 325

82. Mateus TL, Castro A, Ribeiro JN, Vieira-Pinto M, 2014. Multiple zoonotic parasites identified in dog feces collected in Ponte de Lima, Portugal-a potential threat to human health. Int $J$ Environ Res Public Health 11: 9050-9067.

83. Paradies P, larussi F, Sasanelli M, Capogna A, Lia RP, Zucca D, Greco B, Cantacessi C, Otranto D, 2017. Occurrence of strongyloidiasis in privately owned and sheltered dogs: clinical presentation and treatment outcome. Parasit Vectors 10: 345.

84. Rinaldi L, Biggeri A, Carbone S, Musella V, Catelan D, Veneziano V, Cringoli G, 2006. Canine faecal contamination and parasitic risk in the city of Naples (southern Italy). BMC Vet Res 2: 29.

85. Natural Resources Conservation Service, USDA, 2018. Web Soil Survey. Available at: https://websoilsurvey.sc.egov.usda.gov/ App/HomePage.htm. Accessed August 29, 2019.

86. Texas Department of State Health Services, 2019. Texas Notifiable Conditions-2019. Available at: https://www.dshs. texas.gov/IDCU/investigation/Notifiable-Conditions.xls. Acce ssed September 22, 2019.

87. National Notifiable Diseases Surveillance System, Centers for Disease Control and Prevention, 2019. National Notifiable Conditions. Available at: https://wwwn.cdc.gov/nndss/conditions/ notifiable/2019/. Accessed September 22, 2019.

88. Guerra Uribe M, Faust KM, Charnitski J, 2019. Policy driven water sector and energy dependencies in Texas border colonias. Sustain Cities Soc 48: 101568.

89. Durst NJ, 2014. Municipal annexation and the selective underbounding of colonias in Texas' Lower Rio Grande valley. Environ Plan A 46: 1699-1715. 